Communication

\title{
Innovation in Continuous Rectification for Tequila Production
}

\author{
Estarrón-Espinosa Mirna, Ruperto-Pérez Mariela, Padilla-de la Rosa José Daniel * and \\ Prado-Ramírez Rogelio *
}

Centro de Investigación y Asistencia en Tecnología y Diseño del Estado de Jalisco (CIATEJ), Av. Normalistas No. 800, C.P. 44720 Guadalajara, Jalisco, Mexico; mestarron@ciatej.mx (E.-E.M.); mruperto11@gmail.com (R.-P.M.)

* Correspondence: jdpadilla@ciatej.mx (P.-d.1.R.J.D.); rprado@ciatej.mx (P.-R.R.); Tel.: +33-33455200 (P.-d.1.R.J.D.)

Received: 23 March 2019; Accepted: 6 May 2019; Published: 14 May 2019

\begin{abstract}
In this study, a new process of continuous horizontal distillation at a pilot level is presented. It was applied for the first time to the rectification of an ordinario fraction obtained industrially. Continuous horizontal distillation is a new process whose design combines the benefits of both distillation columns, in terms of productivity and energy savings (50\%), and distillation stills in batch, in terms of the aromatic complexity of the distillate obtained. The horizontal process of continuous distillation was carried out at the pilot level in a manual mode, obtaining five accumulated fractions of distillate that were characterized by gas chromatography (GC-FID). The tequila obtained from the rectification process in this new continuous horizontal distillation process complies with the content of methanol and higher alcohols regulated by the Official Mexican Standard (NOM-006-SCFI-2012). Continuous horizontal distillation of tequila has potential energy savings of $50 \%$ compared to the traditional process, besides allowing products with major volatile profiles within the maximum limits established by the regulation for this beverage to be obtained.
\end{abstract}

Keywords: horizontal continuous distillation; rectification; tequila; energy saving

\section{Introduction}

Tequila is a traditional Mexican alcoholic beverage recognized around the world. It is obtained from distillation of the fermented juice of the Agave tequilana Weber blue variety. The production process consists of five stages: cooking, grinding, fermentation, distillation, and resting or aging [1]. According to the percentage of sugars belonging to agave used in the production of Tequila, it can be classified as one of the following categories: Tequila and Tequila 100\% Agave [2]. In the case of Tequila, $51 \%$ of the total sugars in the fermentation process must belong to agave, and the rest of the sugars may be obtained from other sources [3]. The Tequila aroma depends on the amount and type of volatile compounds present [4]. Tequila's composition is very complex. Different volatile compounds have been reported as responsible for the sensorial characteristics of tequila, among which the most important are alcohols, esters, terpenes, fatty acids, aldehydes, ketones, furans, sulphur compounds, lactones, and phenols [4,5]. This composition is affected by each of the stages of its production process, where the distillation process plays an important role. Based on the Official Mexican Standard regulating tequila composition, the maximum permissible concentration of methanol is $300 \mathrm{mg} / 100 \mathrm{~mL}$ of anhydrous alcohol, while for higher alcohols, it is $500 \mathrm{mg} / 100 \mathrm{~mL}$ of anhydrous alcohol [3]. The alcohol concentrations of tequila can be regulated during the distillation process.

Most spirits' production processes use either batch distillation columns or alembics [6]. The latter are the most frequently used in small-scale production facilities. In these systems, three cuts (head, heart, and tail) are collected sequentially; high-quality spirits are produced from the heart cut. Even though 
the operation of alembics is relatively simple compared to batch distillation columns, it involves many uncontrolled and unmeasured disturbances that generate variability in the composition of the final product [7]. Tequila is obtained after two consecutive differential distillations in pot stills [1]. The first one, named stripping, allows a product called ordinario to be obtained, whose ethanol content is 20-30\% in volume. The second one, named rectification, consists of distilling the ordinario again and obtaining three products: head, tail, and heart, the latter of which has an ethanol content close to $55 \%$ in volume, which basically constitutes a tequila beverage [8].

The use of batch distillation columns results in a higher productivity and higher efficiency of ethanol recovery compared to the traditional batch process, but a lower presence of compound complexity in the Tequila product [9].

Recently, innovations have emerged in the distillation area focused on energy reduction, consumption, and process time [10-12]. A new patented technology, called Continuous Distillation [13], has been shown to be more efficient and more cost-effective than the traditional process. Continuous horizontal distillation combines the distillation columns and batch distillation process. This system has reduced the energy consumption by $50 \%$ based on a study where citrus essential oils were obtained [14]. Currently, an equipment prototype of continuous distillation has been built, which consists of five stages, built in stainless steel 304 with an operation volume of $60 \mathrm{~L}$ which operates continuously (Figure 1).

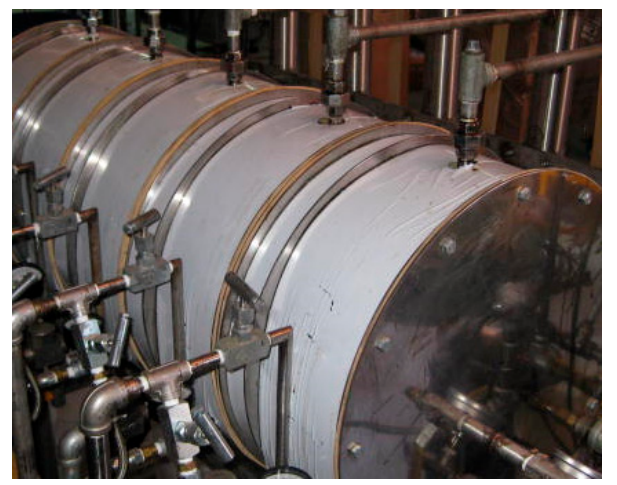

Figure 1. Equipment prototype of continuous distillation.

The information above has led us to apply this distillation process in tequila production, since it has a great potential for application in the tequila industry. This study aims to produce higher productivity and energy savings while preserving the tequila aroma.

In this study, we evaluate the composition of the distilled fractions obtained during the rectification process by continuous distillation of the ordinario obtained at the industrial level, in order to know if this distillation system allows tequila with the quality specified in the Official Standard for tequila to be obtained.

\section{Materials and Methods}

\subsection{Raw Material.}

A total of 250 liters of ordinario with an alcohol content of $26.0 \%$ Alc. Vol. was provided by Tequila San Matías Inc., from the state of Jalisco.

\subsection{Continuous Distillation of Ordinario at Pilot Level.}

The process was operated in manual mode over a period of $4 \mathrm{~h}$ for two experimental runs under the following conditions:

Feed Flow: $60 \mathrm{~mL} / \mathrm{min}(\mathrm{T}=16.67 \mathrm{~h})$.

Distilled-Feed Ratio (D/F) $=0.2 \mathrm{~L}$ distilled/L ordinario Feed. 
It was decided to work at a low flow (high residence times) to ensure the stability of the process since it was operated in manual mode without the control system. In later phases, we intend to work at shorter residence times by making modifications to the equipment.

\section{Process Description}

The liquid to be distilled, in this case ordinario (product of the first distillation), is fed (F) in the first stage (Figure 2) and goes through each of the five stages of the equipment until obtaining the waste stream $(\mathrm{W})$. In each of the stages, both heat exchangers carry out evaporation of the volatiles, which are recovered in each of the five condensers to obtain the distillate (D).

This equipment has a heat recovery system that allows us to recover the heat of the waste (W) to preheat the feed $(\mathrm{F})$, which achieves an additional energy saving in the process when recovering the sensible heat. In each of the condensers, a distilled fraction (D) is obtained, which is characterized and which, according to the desired profile or composition, can be mixed.

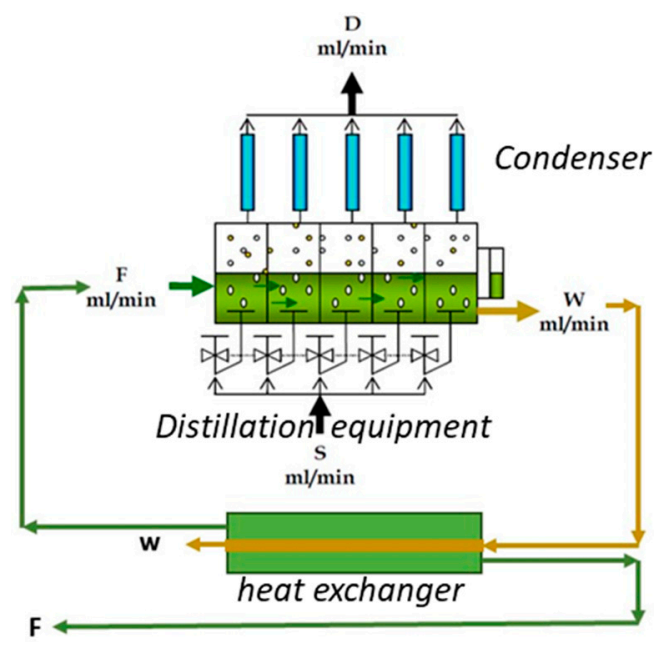

Figure 2. Schematic diagram of continuous distillation.

The accumulated volume of the five distilled fractions obtained was collected and analyzed by gas chromatography to determinate the content of methanol, higher alcohols, esters, furfural, and aldehydes.

\subsection{Alcoholic Content}

Alcohol content expressed as $\%$ ethanol $(v / v)$ at $20{ }^{\circ} \mathrm{C}$ was measured with a portable density meter DMA-35 (Anton Paar, Graz, Austria).

\subsection{Chromatographic Characterization}

The distilled fractions and products (accumulated fractions) were analyzed by gas chromatography (GC) using an Agilent Technologies 7890B gas chromatograph (Palo Alto, CA, USA) equipped with a flame ionization detector (FID). Separation was performed on an INNOWAX capillary column $(60 \mathrm{~m} \times 250 \mu \mathrm{m}$ i.d. $\times 0.25 \mu \mathrm{m}$ film thickness) with nitrogen as the carrier gas $(1 \mathrm{~mL} / \mathrm{min})$. The oven temperature was programmed initially at $50^{\circ} \mathrm{C}$ for $7 \mathrm{~min}$, and was then increased at a rate of $10^{\circ} \mathrm{C} / \mathrm{min}$ to $165^{\circ} \mathrm{C}$. Following this, the temperature was raised from $165^{\circ} \mathrm{C}$ to $220^{\circ} \mathrm{C}$ at a rate of $20^{\circ} \mathrm{C} / \mathrm{min}$ and held for $5 \mathrm{~min}$. A volume of $1 \mu \mathrm{L}$ was injected in split mode with a split ratio of 1:50. The injection port and detector temperatures were 220 and $250{ }^{\circ} \mathrm{C}$, respectively. A mixture of air $(400 \mathrm{~mL} / \mathrm{min})$, hydrogen $(40 \mathrm{~mL} / \mathrm{min})$, and nitrogen as the auxiliary gas $(25 \mathrm{~mL} / \mathrm{min})$ was also fed to the detector. Chromatographic data was collected and recorded using Mass Hunter GC/MS software (B.07.02.1938). Quantification of major volatiles in samples was based on the internal standard method, as described in the Official Mexican Standard, NOM-006-SCFI-2012. The analyses were performed in duplicate and the results were expressed as $\mathrm{mg} / 100 \mathrm{~mL}$ of anhydrous alcohol. 


\subsection{Statistical Analysis.}

An analysis of variance was done to identify differences in the concentration of compounds regulated by the Official Standard (NOM-006-SCFI-2012) for each fraction using the statistical software STATGRAPHICS CENTURION XVI.

\section{Results and Discussions}

\subsection{Alcoholic Concentration of Distilled Fractions}

The average distillates of the fractions of continuous distillation had an alcoholic grade of $57.2 \% \pm 12.6$ Alc. Vol., which was similar to the distillate obtained by batch distillation [8] (Figure 3).

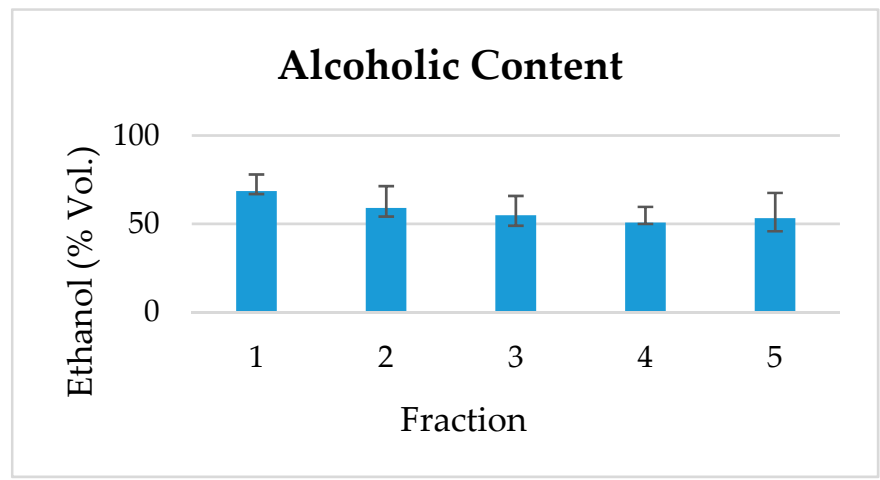

Figure 3. Alcoholic degree of the distilled fractions obtained in the continuous distillation.

\subsection{Chromatographic Characterization}

\subsubsection{Content of Higher Alcohols and Aldehydes}

The five accumulated fractions of distillate obtained in the continuous distillation process showed statistically significant differences among themselves regarding the content of aldehydes and higher alcohols, with fraction 1 showing the highest amount of higher alcohols and aldehydes, with an average content of $253.66 \pm 86.51$ and $2.87 \pm 1.02 \mathrm{mg} / 100 \mathrm{~mL}$ of anhydrous alcohol, respectively (Figure 4). The variation of acetaldehyde (Figure $4 \mathrm{~b}$ ), which is a very volatile compound, may be due to changes in the temperature of the process due to the equipment that was operated in manual mode.

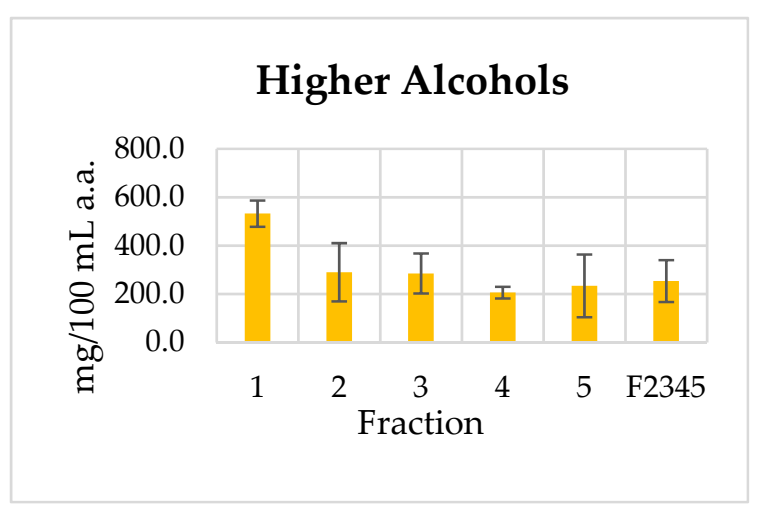

(a)

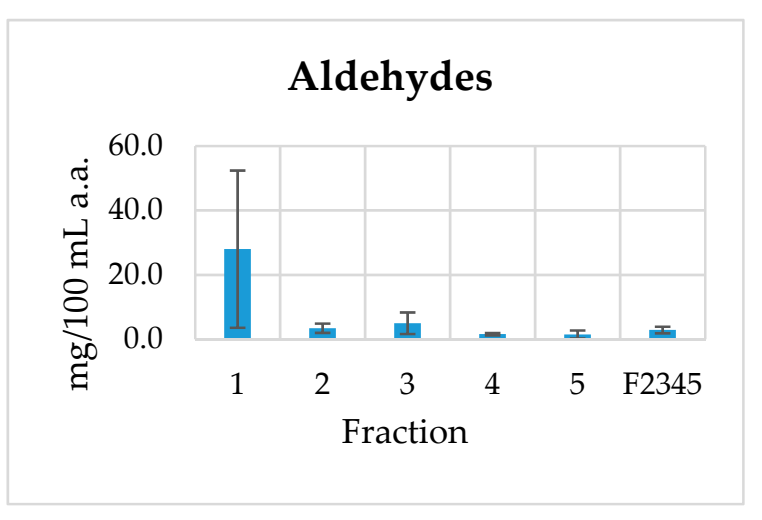

(b)

Figure 4. Concentration of higher alcohols (a) and aldehydes (b) in different collected fractions.

Fraction 1 obtained in the continuous distillation system was equivalent to heads in the batch distillation and could be removed to obtain a final product with a better aromatic profile. 


\subsubsection{Content of Methanol, Esters, and Furfural}

The four accumulated fractions 2, 3, 4, and 5 (F2345) of distillate obtained in the distillation process did not show statistically significant differences with a $95 \%$ confidence level. An average concentration of $95.17 \pm 4.59,11.67 \pm 3.56$, and $1.18 \pm 0.35 \mathrm{mg} / 100 \mathrm{~mL}$ of anhydrous alcohol was determined for methanol, esters, and furfural, respectively (Figure 5).

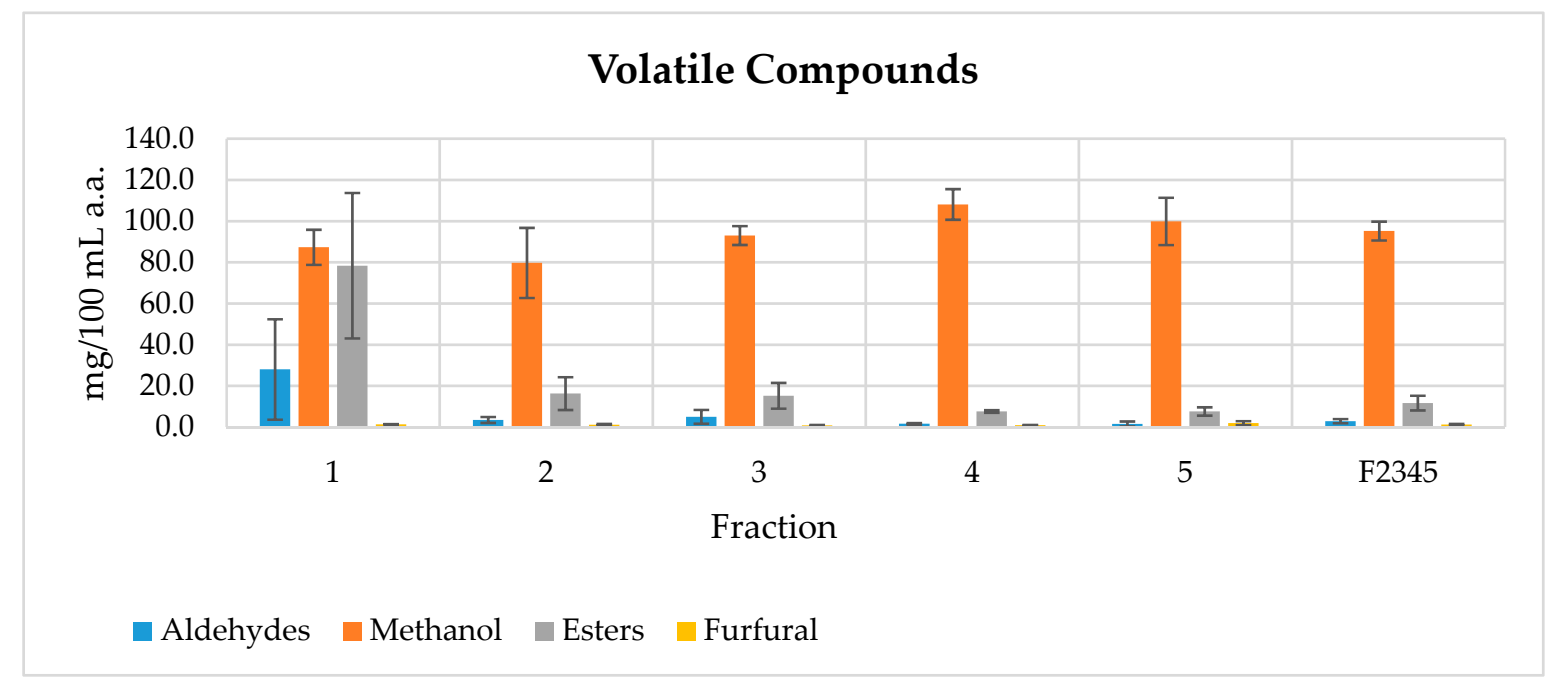

Figure 5. Concentration of methanol, esters, and furfural in different collected fractions.

The final distillate obtained, which consisted of the mixture of fractions 2, 3, 4, and 5 (F2345), was below the maximum permissible limits regarding the content of methanol, higher alcohols, esters, and aldehydes established by the Official Mexican Standard for Tequila (NOM-006-SCFI-2012) [3] (Table 1).

Table 1. Results of the major volatile profile for the final distillate obtained by continuous distillation.

\begin{tabular}{|c|c|c|}
\hline Compound & $\begin{array}{l}\text { Mean concentration of Continuous Distillation } \\
(\Sigma \text { Fractions } 2,3,4 \text { and } 5) . \mathrm{mg} / 100 \mathrm{~mL} \text { of a. a. }\end{array}$ & $\begin{array}{l}\text { NOM-006-SCFI-2012 } \\
\text { mg/100 mL of a. a. }\end{array}$ \\
\hline Aldehydes & $2.87 \pm 1.02$ & 40 \\
\hline Methanol & $95.17 \pm 4.59$ & 300 \\
\hline Esters & $11.67 \pm 3.56$ & 200 \\
\hline Higher alcohols & $253.66 \pm 86.51$ & 500 \\
\hline Furfural & $1.18 \pm 0.35$ & 4 \\
\hline
\end{tabular}

Different authors have reported the concentration increase of several compounds during distillation [5], while with this process (Table 1), the content of methanol and higher alcohols is maintained below the limits established by the Mexican regulation of tequila [3]. In addition to reducing the energy consumption, multiple options are generated by being able to mix the fractions of interest to reduce methanol contents and/or higher alcohols at the end of the process (Table 2). 
Table 2. Chromatographic characterization of tequila fractions of continuous distillation.

\begin{tabular}{cccccc}
\hline \multirow{2}{*}{ Compound } & Fraction 1 & Fraction 2 & Fraction 3 & Fraction 4 & Fraction 5 \\
\cline { 2 - 6 } & Mean \pm S.D. & Mean \pm S.D. & Mean \pm S.D. & Mean \pm S.D. & Mean \pm S.D. \\
\hline Acetaldehyde & $27.97 \pm 24.40$ & $5.05 \pm 1.44$ & $4.97 \pm 3.35$ & $1.57 \pm 0.36$ & $1.50 \pm 1.23$ \\
Ethyl acetate & $76.48 \pm 35.56$ & $13.04 \pm 8.35$ & $11.83 \pm 7.26$ & $2.91 \pm 0.66$ & $2.87 \pm 3.77$ \\
Methanol & $87.28 \pm 8.53$ & $81.11 \pm 17.03$ & $93.02 \pm 4.58$ & $108.10 \pm 7.42$ & $99.84 \pm 11.48$ \\
2-Butanol & $1.19 \pm 0.04$ & $0.41 \pm 0.23$ & $0.39 \pm 0.41$ & $0.21 \pm 0.08$ & $0.34 \pm 0.36$ \\
1-Propanol & $30.49 \pm 2.35$ & $20.62 \pm 7.21$ & $22.42 \pm 3.79$ & $20.43 \pm 1.07$ & $20.66 \pm 5.65$ \\
Isobutanol & $148.66 \pm 13.97$ & $72.08 \pm 32.46$ & $74.63 \pm 22.91$ & $52.47 \pm 6.06$ & $59.21 \pm 34.63$ \\
1-Butanol & $0.99 \pm 0.15$ & $0.60 \pm 0.21$ & $0.59 \pm 0.20$ & $0.56 \pm 0.03$ & $0.64 \pm 0.33$ \\
Isoamyl alcohol & $350.58 \pm 38.21$ & $180.16 \pm 80.52$ & $186.35 \pm 55.65$ & $131.83 \pm 17.22$ & $152.55 \pm 88.84$ \\
1-Pentanol & $0.32 \pm 0.12$ & $0.37 \pm 0.06$ & $0.55 \pm 0.22$ & $0.36 \pm 0.09$ & $0.46 \pm 0.12$ \\
Ethyl lactate & $1.87 \pm 0.55$ & $2.82 \pm 0.50$ & $3.38 \pm 1.07$ & $4.70 \pm 1.09$ & $4.72 \pm 2.53$ \\
Furfural & $1.35 \pm 0.11$ & $1.00 \pm 0.36$ & $0.81 \pm 0.26$ & $0.86 \pm 0.16$ & $1.92 \pm 0.96$ \\
\hline
\end{tabular}

\subsection{Energy Consume}

Distillation uses a lot of energy; however, with a good design of the system, the energy requirements can be reduced or recovered for other operations [14]. Another alternative used is mechanical re-compression, but it is costly to install and run so the savings must make it cost effective. About $25 \%$ (depending on design) of the steam emitted from the thermocompressor is recovered heat from the liquid [14].

The horizontal column distillation reduces the consumption of steam by approximately $50 \%$ with respect to the traditional process. The energy consumption of this technology (horizontal continuous distillation) is within the consumption range of the distillation columns and its consumption is approximately $50 \%$ lower than the traditional processes (Table 3).

Table 3. Energy consumption of the different distillation processes.

\begin{tabular}{ccc}
\hline Process & Energy Consume & Reference \\
\hline Batch & $0.87 \mathrm{Kg}$. Vap./Kg Ordinario & {$[15]$} \\
Conventional Column & $0.5-0.6 \mathrm{Kg}$. Vap./Kg Feed & {$[16]$} \\
Kaibel column & $0.4 \mathrm{Kg}$. Vap./Kg Feed & {$[17]$} \\
Horizontal Continuous Distillation & $0.4 \mathrm{Kg}$. Vap./Kg Ordinario & This study \\
\hline
\end{tabular}

The energy saved resides in two main aspects:

1. Multistage distillation is more efficient than one-stage distillation for the same consumption of steam for both alternatives, due to an increment of mass transfer by a higher gradient between concentrations of phase liquid to phase vapor during the distillation process and the better distribution of vapor in each stage;

2. In this technology, it is possible recuperate about $15 \%$ of sensible heat of the effluent using a heat exchanger to preheat the feed, which is a possibility to implement in the beverage industry.

Another potential benefit could be the production of vinasse at a low temperature of $55^{\circ} \mathrm{C}$, facilitating its disposition. Comparatively, a typical Tequila distillery generates 7 to $10 \mathrm{~L}$ of this effluent per liter of Tequila, with a low $\mathrm{pH}$ of 4.5 , high temperature of $95^{\circ} \mathrm{C}$, and high organic loads, which represent a significant disposal problem [18].

In terms of the economic aspect, the distillation represents around $50 \%$ of energetic consumption in the elaboration process of tequila. A reduction of $50 \%$ of the energy of distillation results in an energy consumption reduction of $25 \%$ in the global process. For a $100 \%$ tequila producing plant of $852,120 \mathrm{~L} /$ year where steam consumption represents $0.29 \%$ of the cost structure [19], these numbers are apparently low, permitting us to keep distillated fractions of high value-added and the potential control of the compounds responsible for the aroma of tequila within the limits allowed [3]. 


\section{Conclusions}

The tequila obtained from the rectification process in this new continuous horizontal distillation process complies with the content of major volatiles (methanol and higher alcohols) regulated by the Official Mexican Standard. The five accumulated fractions of distillate obtained in the continuous distillation process did not show statistically significant differences with a $95 \%$ confidence level ( $p$-value $>0.05$ ) with respect to the content of methanol, esters, and furfural. However, these fractions showed statistically significant differences with a $95 \%$ confidence level $(p$-value $<0.05)$ among themselves regarding the content of aldehydes and higher alcohols, with the fraction of 1 being the one that showed the highest amount of both groups of compounds.

Continuous horizontal distillation constitutes a potential alternative for the distillation of tequila with the benefit of energy savings of $50 \%$ compared to the traditional process and the potential control of the compounds regulated by the Official Mexican Specification for tequila.

Author Contributions: P.-d.1.R.J.D. and P.-R.R. directed the research, E.-E.M. and P.-d.1.R.J.D. supported work in the redaction and reviewed the paper, and R.-P.M. realized the experimentation.

Funding: This research received no external funding.

Acknowledgments: We acknowledge CIATEJ for the facilities and support during the development of the present work; Tequila San Matías Inc., from the state of Jalisco, for providing the ordinary tequila; and Tec. Abiel Alba and Ing. Ernesto Rodríguez for the technical support during the development of the experiment.

Conflicts of Interest: The authors declare no conflict of interest.

\section{References}

1. Cedeño, M.C. Tequila Production. Crit. Rev. Biotechnol. 1995, 15, 1-11. [CrossRef] [PubMed]

2. Consejo Regulador del Tequila. Available online: http://www.crt.org.mx (accessed on 15 January 2019).

3. Secretaría de Economía. Bebidas Alcohólicas-Tequila-Especificaciones; NOM-006-SCFI-2012; Secretaría de Economía: México City, México, 2012.

4. Benn, S.M.; Peppard, T.L. Characterization of Tequila Flavor by Instrumental and Sensory Analysis. J. Agric. Food Chem. 1996, 44, 557-566. [CrossRef]

5. Prado-Jaramillo, N.; Estarrón-Espinosa, M.; Escalona-Buendía, H.; Cosío-Ramírez, R.; Martín-del-Campo, S.T. Volatile compounds generation during different stages of the Tequila production process. A preliminary study. LWT-Food Sci. Technol. 2015, 61, 471-483. [CrossRef]

6. Luna, R.; López, F.; Pérez-Correa, J.R. Minimizing methanol content in experimental charentais alembic distillations. J. Ind. Eng. Chem. 2018, 57, 160-170. [CrossRef]

7. Rogelio, P.-R.; Victor, G.-A.; Carlos, P.-O.; Norberto, C.; Mirna, E.; Héctor, E.G.-H. The role of distillation on the quality of tequila. Int. J. Food Sci. Technol. 2005, 40, 701-708. [CrossRef]

8. Batista, F.R.M.; Meirelles, A.J.A. Computer simulation applied to studying continuous spirit distillation and product quality control. Food Control. 2011, 22, 1592-1603. [CrossRef]

9. Sahraoui, N.; Vian, M.A.; Bornard, I.; Boutekedjiret, C.; Chemat, F. Improved microwave steam distillation apparatus for isolation of essential oils: Comparison with conventional steam distillation. J. Chromatogr. A 2008, 1210, 229-233. [CrossRef] [PubMed]

10. Vorayos, N.; Kiatsiriroat, T.; Vorayos, N. Performance analysis of solar ethanol distillation. Renew. Energy 2006, 31, 2543-2554. [CrossRef]

11. Maiti, D.; Jana, A.K.; Samanta, A.N. A novel heat integrated batch distillation scheme. Appl. Energy 2011, 88, 5221-5225. [CrossRef]

12. Padilla, J.D.; Vega, H.; Alba, A.; Rodríguez, E. Sistema Multifuncional de Destilación, Evaporación y Extracción de Moléculas orgánicas Derivadas de Productos Naturales. MX Patent No. 013248, 9 December 2011.

13. Padilla, M.F.J; González, R.O.; Prado, R.R.; Gutiérrez, P.H.; Estarrón, E.M.; Vega, G.H.A.; Padilla de la R, J.D. Nuevo equipo y proceso de destilación fraccionada en continuo por arrastre con vapor de aceites esenciales del jugo de limón mexicano. E-Gnosis 2007, 5, 1-16. 
14. Piggot, R. From pot stills to continuous stills: Flavor modification by distillation. In The Alcohol Textbook, 4th ed.; Jacques, K.A., Lyons, T.P., Kelsall, D.R., Eds.; Nottingham University Press: Nottingham, UK, 2003; pp. 259-266.

15. Velásquez, H.I.; Adriana Ruiz, A.A.; Junior, S. Energy and exergy analysis of etanol production process from banana fruit. Rev. Fac. Ing. Univ. Antioquia 2010, 51, 87-96.

16. Wakabayashi, T.; Yoshitani, K.; Takahashi, H.; Hasebe, S. Verification of energy conservation for discretely heat integrated distillation column through commercial operation. Chem. Eng. Res. Des. 2019, 142, 1-12. [CrossRef]

17. Wang, X.; Yu, X.; Xie, L.; Li, M.; Zhang, Y. Energy-saving columns: Design and control of a Kaibel and a multi-sidestream column for separating hydrocarbon mixture. Chem. Eng. Process. Process Intensif. 2018, 133, 66-82. [CrossRef]

18. Alemán-Nava, G.S.; Gatti, I.A.; Parra-Saldivar, R.; Dallemand, J.-F.; Rittmann, B.E.; Iqbal, H.M.N. Biotechnological revalorization of Tequila waste and by-product streams for cleaner production-A review from bio-refinery perspective. J. Clean. Prod. 2018, 172, 3713-3720. [CrossRef]

19. Martínez Morales, M.; Pérez Alvarado, E.; Garfias Lopez, L. Análisis del Mercado Potential del Tequila 100\% Agave; Tesis de pregrado; Instituto Politécnico Nacional: México City, México, 2008.

(C) 2019 by the authors. Licensee MDPI, Basel, Switzerland. This article is an open access article distributed under the terms and conditions of the Creative Commons Attribution (CC BY) license (http://creativecommons.org/licenses/by/4.0/). 